\title{
Fractionation and recovery of secretions of synovial cells synthesized in culture with radioactive precursors
}

\author{
E. BAXTER, J. R. E. FRASER, AND G. S. HARRIS \\ From the University of Melbourne Department of Medicine, The Royal Melbourne Hospital, \\ Victoria, Australia
}

The synthesis of many constituents of connective tissues, including glycosaminoglycans (Grossfeld, Meyer, Godman, and Linker, 1957), collagen (Jackson and Smith, 1957; Porter and Pappas, 1959), collagenase (Evanson, Jeffrey, and Krane, 1967) and a protein immunologically cross-reactive with chondromucoprotein (Janis, Sandson, Smith, and Hamerman, 1967), has been widely studied in cell cultures from synovium and related tissues.

For all but brief intervals, the culture medium for these cells must contain natural nutrients such as serum, which sets a problem in distinguishing the macromolecules secreted by the cells from those added with the medium. This can be overcome in many ways, ranging from simple comparison of cellexposed and control medium with the mucin clot test, to electron microscopy, isotopic tracing, immunochemistry, and complicated chemical extractions. In identification or measurement of the secretions, some minor degradation might not matter; but their separation in the native state from the great excess of extraneous material in culture medium is quite a different exercise, especially in the case of hyaluronic acid which is singularly prone to physical and chemical degradation (Ogston and Stanier, 1952).

For the production of undegraded radioactive hyaluronic acid by cell culture, we have preferred chromatography in the cross-linked dextran, Sephadex G200, as the initial step in the treatment of the culture medium (Fraser, 1963). The introduction of agarose gels for fractionation of synovial fluid (Barker and Young, 1966) has made the purification of cell-secreted hyaluronic acid virtually a one-stage process. However, Sephadex G200 also separates other classes of secretion of potential interest. It is the purpose of this paper to report experience accumulated with these methods of analyzing cell-culture secretions formed from glucose and other simple substrates.

Accepted for publication July 6, 1972.

\section{Material and methods}

\section{CELL CULTURES}

These were obtained as primary cell dispersions in trypsin from intact human knee joints, and established in 'Pyrex' glass or polystyrene plastic (Falcon) flasks with medium 199 containing 20 per cent. each of heat-inactivated human and foetal calf serum. Other details of culture and media have been given elsewhere (Fraser and McCall, 1965; Clarris and Fraser, 1968a).

HYALURONIDASES

These were kindly given by N. V. Organon, Oss. Activities were 10,900 i.u./mg. bacterial enzyme and 630 i.u./mg. testicular enzyme.

\section{CHROMATOGRAPHIC GELS}

The dextran gels (Sephadex G200 and G15, Pharmacia) were equilibrated with phosphate-buffered saline (Dulbecco and Vogt, 1954). Granulated 2 per cent. agarose gel (Sagarose 2, Seravac, Berks.) was equilibrated with Tris$\mathrm{HCl}$ buffer, 0.05 M, pH 7.7. Several columns were used with gel volumes ranging from 70 to $350 \mathrm{ml}$., and diameters from 1 to $3.5 \mathrm{~cm}$. The volume of samples were restricted to 2 per cent. or less of the total gel bed volume, and the eluate collected in fractions of 1 to $3 \mathrm{ml}$. Outflow was monitored and collected with LKB Uvicord recorder and fraction collector.

\section{RADIOACTIVE SUBSTRATES}

These were obtained from the Radiochemical Centre, Amersham, and were uniformly labelled. Final activities expressed as $\mu \mathrm{c} / \mathrm{ml}$. culture medium were: ${ }^{14} \mathrm{C}$-glucose, $2 \cdot 5 ;{ }^{3} \mathrm{H}$-glucose, $2 \cdot 5 ;{ }^{14} \mathrm{C}$-leucine, $2.0 ;{ }^{14} \mathrm{C}$-tryptophane, $3 \cdot 3 ;{ }^{14} \mathrm{C}$-proline, $5 \cdot 0$.

ESTIMATION OF RADIOACTIVITY

0.2-ml. samples were added to $10 \mathrm{ml}$. Bray's fluid (Bray, 1960) and radioactivity was counted in a Packard Model 314 Ex liquid scintillation counter. Absolute activity was not estimated. Fractions on paper and cellulose acetate were located with a Packard Radiochromatogram Scanner.

INTRODUCTION OF SUBSTRATES TO CULTURES

The cells were used either as clearly established and vigorous primary cultures, i.e. about 3 to 10 days after isolation, or in the third or fourth subculture 3 to 5 weeks later. The 
cultures were thoroughly rinsed with Hanks's balanced salt solution, and the radioactive substrate introduced in medium 199 with 20 per cent. human serum, with or without 10 per cent. foetal calf serum. After 4 or 5 days incubation at $37^{\circ} \mathrm{C}$, this medium was decanted, filtered through fibreglass, centrifuged, and stored at $-20^{\circ} \mathrm{C}$.

Other methods and sources of materials will be quoted where appropriate.

\section{Results}

Elution through Sephadex G200 gave a common pattern superimposed upon that of the serum proteins in the media. The serum proteins appeared in the continuous sequence described and analysed by Flodin and Killander (1962); a first peak representing the macroglobulins in the excluded volume, followed usually by a second less distinct peak of 7S globulins and proteins of similar size, and a third large peak of albumin and smaller globulins.

Radioactivity which had presumably been synthesized in cell-secreted macromolecules appeared in two distinct fractions: the first in the excluded volume, and the second, which was not always present, associated with the albumin peak. Unutilized radioactive substrates followed the last proteins, and phenol red from the medium 199 was well retarded.

The possibility of simple adsorption of substrate to serum proteins was variously excluded:

(1) By control gel chromatography:

(a) Of radioactive substrate incubated in media without cells;

(b) Of test media first dialysed with non-radioactive substrate;

(2) By subsequent treatment of the macromolecular fractions.

The two classes of these secretions as defined by G200 will be referred to as Fr. 1 and Fr. 2.

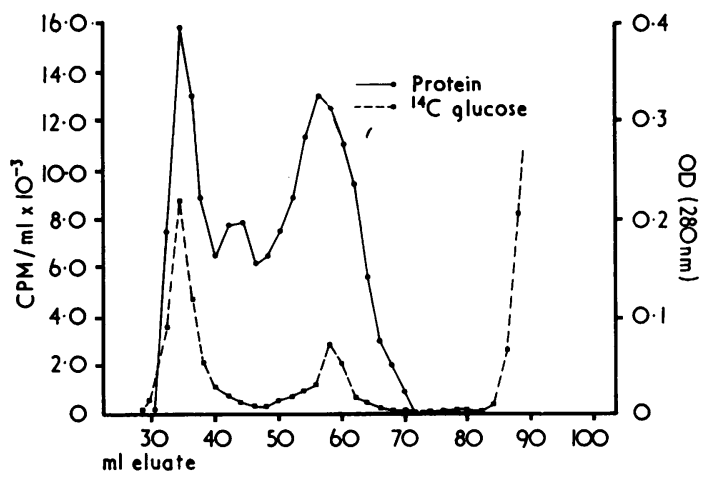

FIG. 1 Cell culture medium containing ${ }^{14} C$-glucose. Elution profile from Sephadex G200

- Protein as optical density at $280 \mathrm{~nm}$

...- Radioactivity in counts per min. per ml. eluate
${ }^{14}$ C-GLUCOSE AS SUBSTRATE

Elution from Sephadex G200

Radioactivity was shown, with one exception, to appear in the two fractions, though the relative proportions varied greatly. Fr. 1 sometimes predominated as in Fig. 1. The ratio of Fr. 1:Fr. 2 was usually about $2: 1$, but sometimes as little as $1: 2$. No reason for this variation has been clearly recognized.

Samples of Fr. 1 were pooled, dialysed against water, concentrated in vacuo with $\mathrm{P}_{2} \mathrm{O}_{5}$ until reduced to the volume of the original culture-medium sample, and dialysed against phosphate-buffered saline. 95 per cent. of the radioactivity of an aliquot was recovered by precipitation with Scott's aliphatic quaternary ammonium $\left(\mathrm{QN}^{+}\right)$method (Scott, 1960) modified for cell culture medium (Harris and Fraser, 1969). Less than 10 per cent. reappeared in the macromolecular zone of elution from G200 after $16 \mathrm{hrs}$ ' treatment at $37^{\circ} \mathrm{C}$. with bacterial hyaluronidase 100 i.u./ml. Elution through Sephadex G15 (exclusion limit at M.W. 1500) confirmed the degree of enzymic degradation (Fig. 2).

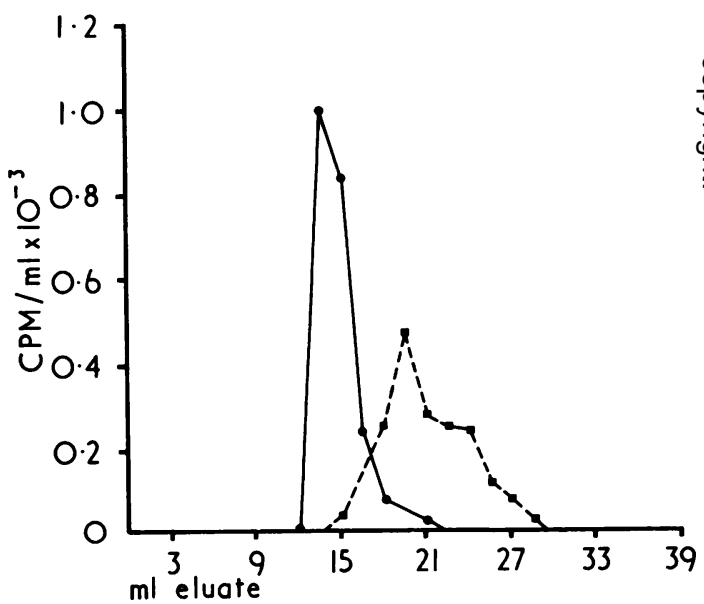

FIG. 2 Elution profiles from Sephadex G15 to show degradation of ${ }^{14} \mathrm{C}$-glucose-labelled Fr. 1 from Sephadex G200 (See text)

Control sample: radioactivity appearing in excluded volume

-. - - Sample treated with bacterial hyaluronidase: elution of radioactivity retarded

Samples of Fr. 2 were concentrated and dialysed as above. Only 5 to 15 per cent. of the radioactivity was precipitated with $\mathrm{QN}^{+}$, and less than 10 per cent. was lost on dialysis after treatment with testicular hyaluronidase in the same manner as with the bacterial enzyme.

In redissolved extracts, obtained from $10 \mathrm{ml}$. pools of Fr. 1 and Fr. 2 by precipitation with $\mathrm{QN}^{+}$, glucuronic acid was detected by the carbazole reaction in Fr. 1 only. 


\section{Elution from agarose}

Results are shown in Fig. 3. A radioactive zone appeared well before the first detectable serum proteins, which indicated very large macromolecules. The pattern closely resembled that obtained with native synovial fluid by Barker and Young (1966) and subsequently in this laboratory, where normal hyaluronic acid appears before any serum protein. Analysis of this by controlled treatment with bacterial hyaluronidase and Sephadex G15 gave the same results as with No. 1 from G200.

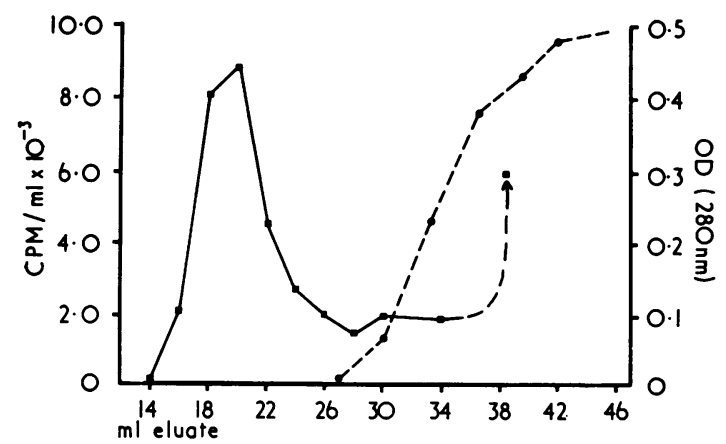

FIG. 3 Cell culture medium containing ${ }^{14}$ C-glucose. Elution profile from agarose (Sagarose 2)

Radioactivity $\quad$ - - O Optical density at $280 \mathrm{~nm}$

Acid hydrolysis

Samples of the front of the radioactive peak from agarose were concentrated and dialysed against water. Brief hydrolysis of one sample yielded evidence of glucuronic acid and hexosamine (Fig. 4).

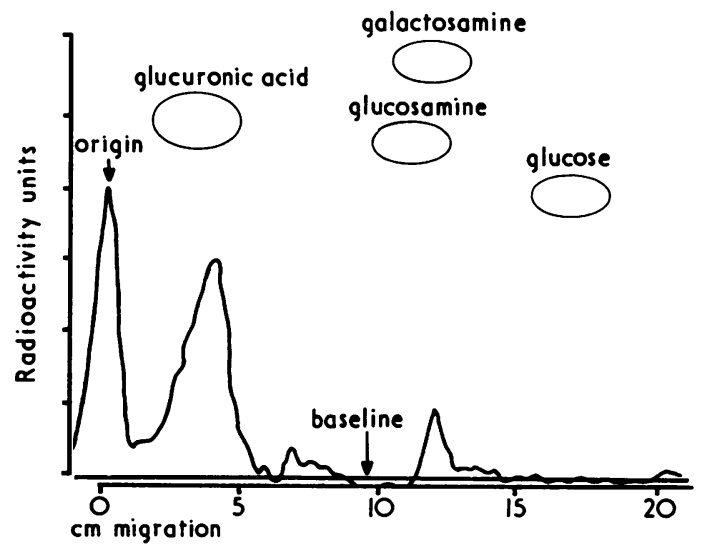

FIG. 4 Paper chromatogram of hydrolysate of ${ }^{14} \mathrm{C}$ glucose-labelled secretion. First fractions from agarose column concentrated, sealed, and heated with 2.5 per cent. $\mathrm{H}_{2} \mathrm{SO}_{4}(\mathrm{v} / \mathrm{v})$ for $2 \mathrm{hrs}$ at $100^{\circ} \mathrm{C}$. Neutralized with $\mathrm{BaCO}_{3}$. Ascending pattern developed on Whatman No. 1 paper in propanol:water, 4:1, for $24 \mathrm{hrs}$. Reference standards located with aniline hydrogen phthalate, radioactivity by scanning (arbitrary units)

More exhaustive hydrolysis suggested that the latter was glucosamine, but the activity was low (Fig. 5).

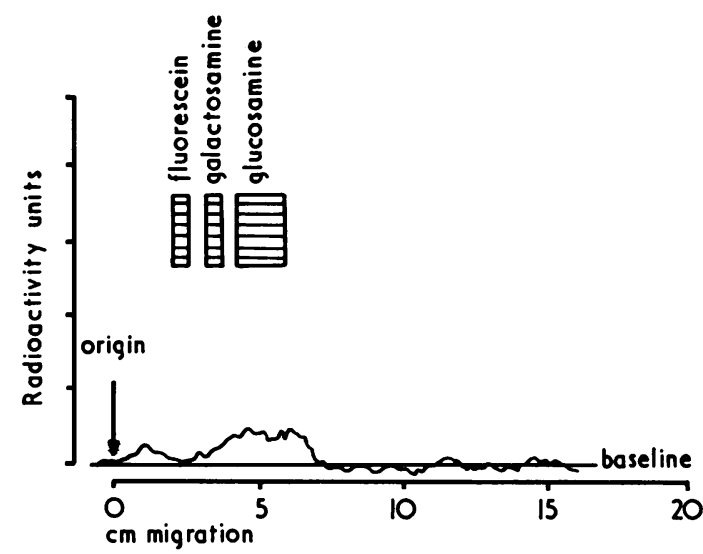

FIG. 5 Paper electrophoresis of sample of same batch as Fig. 4. Hydrolysis with $4 \mathrm{M} \mathrm{HCl}$ for $16 \mathrm{hrs}$ at $100^{\circ} \mathrm{C}$. Acid removed in vacuo, residue conjugated with fluorescein isothiocyanate for electrophoresis in molybdate buffer (Method of Scott, 1962). Reference standards located in ultraviolet radiation, radioactivity by scanning.

\section{Cell-bound hyaluronic acid}

A small fraction of secreted glycosaminoglycan adheres strongly to certain cells in culture. In the case of cartilage cells, it develops as stainable matrix, but in other types of cell it is a clear invisible gel (Clarris and Fraser, 1968b), first discovered because it was released only after trypsin treatment (Daniel, Dingle, and Lucy, 1961). An estimate of this fraction in synovial cell cultures was therefore made with isotopes in the present study. After 3 days' incubation, radioactive glycosaminoglycan free in the medium of replicate cultures was estimated by $\mathrm{QN}^{+}$precipitation. The cell layers were gently washed ten times with $3 \mathrm{ml}$. medium 199, when radioactivity was no longer detected in the wash. Radioactivity released by two treatments of the cell layers with bacterial hyaluronidase ( 320 i.u. in $4 \mathrm{ml}$. for $30 \mathrm{~min}$. at $37^{\circ} \mathrm{C}$.) formed 4 per cent. of the total estimated hyaluronic acid in the culture-a result similar to that obtained by other means of estimation (Castor and Fries, 1961). Activity in the hyaluronic acid was $21 \times 10^{3}$ counts/ $\min . / \mu \mathrm{g}$.

\section{${ }^{14} \mathrm{C}$-AMINOACIDS AND OTHER SUBSTRATES}

Leucine and tryptophane both appeared in Fr. 1 and Fr. 2, and were presumed to have been synthesized in proteins, since neither is likely to be transformed to saccharide. Proline appeared in Fr. 1 only (as did a relatively small amount of ${ }^{35} \mathrm{~S}_{\text {from }}{ }^{35} \mathrm{SO}_{4}$ ).

In the case of leucine, which was studied repeatedly, the ratios of Fr. 1:Fr. 2 varied as much as with glucose. Leucine-labelled material was not precipitated by $\mathrm{QN}^{+}$, and resisted breakdown by hyaluronidase. A small fraction of radioactivity was retarded in the gel column after hyaluronidase treatment. Its position in the elution profile indicated a molecular 
size consistent with either a residue of leucine or an oligopeptide that had been firmly bound to the macromolecules of Fr. 1, and separated only after the several prior treatments (Fig. 6). One study done with ${ }^{3} \mathrm{H}$-glucose and ${ }^{14} \mathrm{C}$-leucine showed ${ }^{14} \mathrm{C}$ and ${ }^{3} \mathrm{H}$ in both Fr. 1 and Fr. 2. The relative abundance of ${ }^{3} \mathrm{H}$ c.f. ${ }^{14} \mathrm{C}$ was greater in Fr. 1 than Fr. 2. Leucine- and tryptophane-labelled samples treated with hyaluronidase and eluted through agarose both gave zones of radioactivity in front of the first serum proteins.

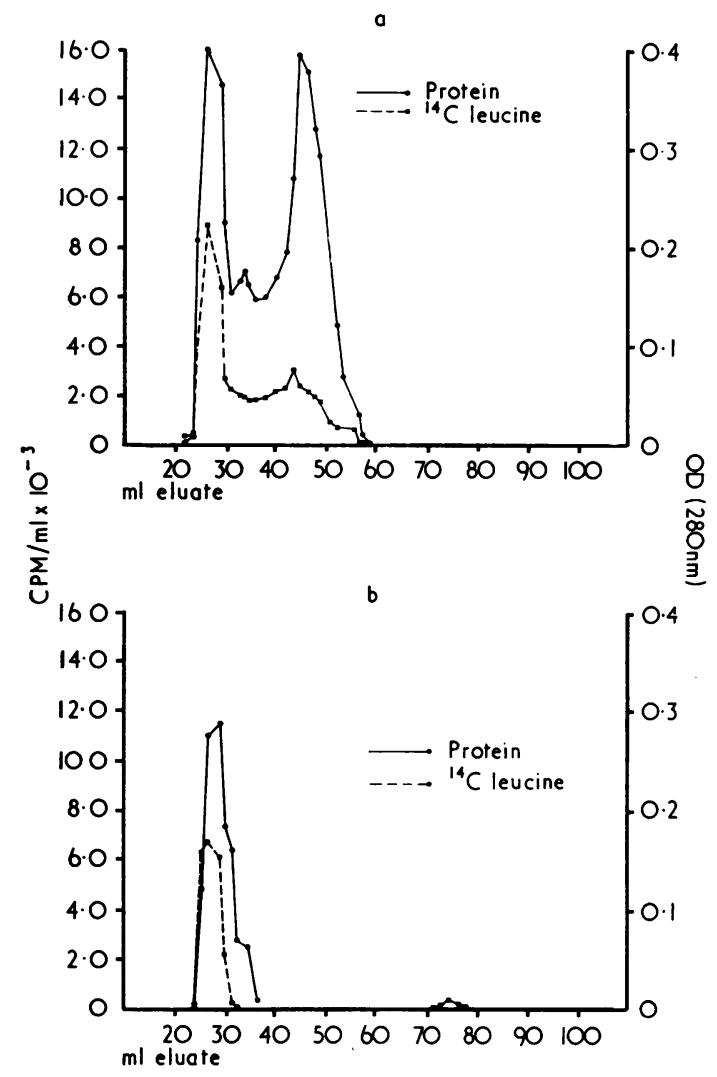

FIG. 6 Cell culture medium containing ${ }^{14}$ C-leucine. Elution profile from Sephadex G200. Ordinates as in Fig. 1

(a) Upper diagram-whole medium

(b) Lower diagram - first zone eluted again after concentration and treatment with bacterial hyaluronidase

\section{ELECTROPHORESIS}

Samples of Fr. 1 and Fr. 2 were dialysed against non-radioactive substrate in $0.15 \mathrm{M} \mathrm{NaCl}$, concentrated, and dialysed against buffer for controlled hyaluronidase treatment of aliquots. These were concentrated again for electrophoresis.

Electrophoresis of Fr. 1 on cellulose acetate was marred either by endosmosis or retention at the roigin. Better definition was attained in acrylamide gels, especially after hyaluronidase. In gel, radio- activity consistently appeared in a zone with mobility about that of $\beta$ globulins, apart from that retained at the origin (Fig. 7). Comparison of Figs 7(a) and (b) shows considerable redistribution of the radioactivity between the origin and the $\beta$ zone after treatment with hyaluronidase. This suggests that the electrophoretic migration of the protein was hindered by retention with hyaluronic acid which cannot penetrate 7.5 per cent. acrylamide gel. Such a retardation can be attributed to hindered diffusion or to some kind of bonding, and is a common problem in the separation of highly polymerized hyaluronic acid and protein by other means, especially paper electrophoresis.
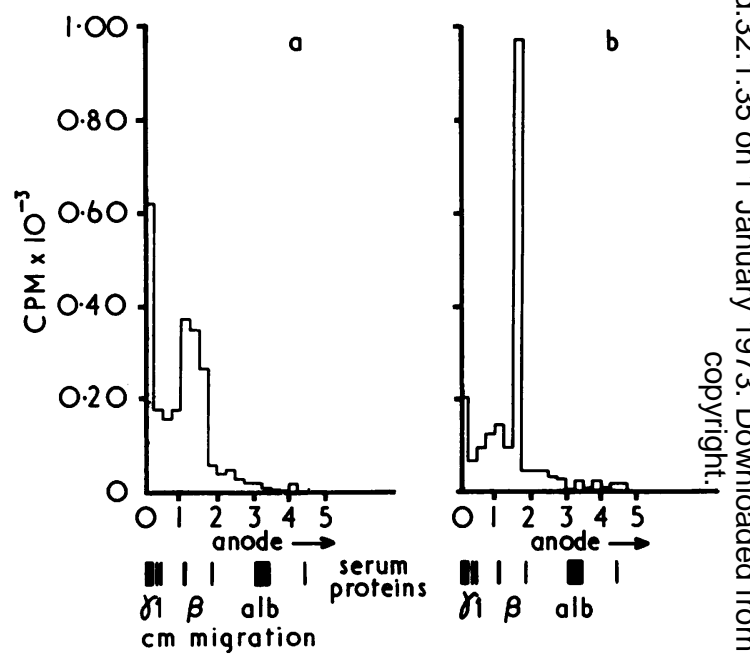

FIG. 7 Cell culture medium containing ${ }^{14} \mathrm{C}$-leucine. Fr. 1 from G200 concentrated and subjected to electrophoresis in 7.5 per cent. polyacrylamide gel. Cut in $2.5 \mathrm{~mm}$. sections and dissolved for scintillation counting by method of Tishler and Epstein (1968). Migration of serum proteins in separately stained gels shown below

(a) control sample

(b) sample treated with bacterial hyaluronidase

In Fr. 2, a major zone of radioactivity with glucose or leucine label migrated in gel or on cellulose acetate at a rate 25 to 80 per cent. greater than that of serum albumin (Fig. 8).

Migration of these two major zones varied with the support used. The band characteristic of each primary fraction (Fr. 1 or Fr. 2) sometimes appeared in the other fraction presumably due to incomplete separation in initial gel chromatography.

\section{Discussion}

Barland, Smith, and Hamerman (1968) have noted that only 30 per cent. of macromolecules synthesized from isotopic glucose by synovial cell cultures appears to be hyaluronic acid, as judged by the fraction 


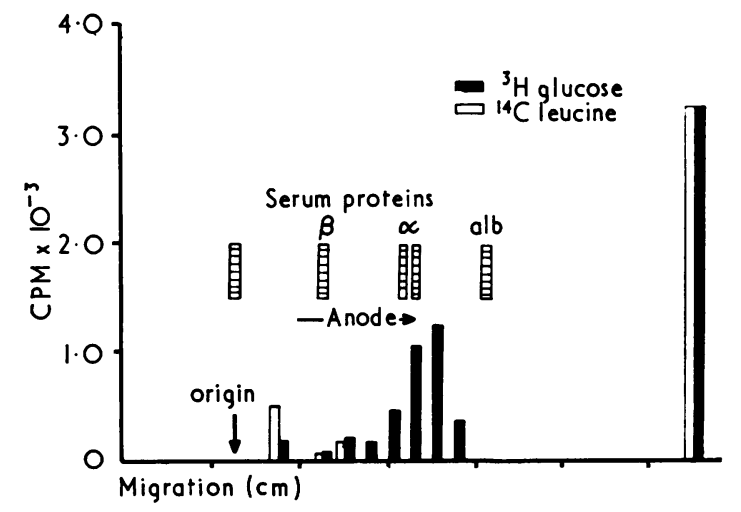

FIG. 8 Cell culture medium containing ${ }^{14} \mathrm{C}$-leucine and ${ }^{3} \mathrm{H}$-glucose. Fr. 2 from $\mathrm{G} 200$, concentrated and subjected to electrophoresis for $1 \mathrm{hr}$ in barbitone- $\mathrm{HCl}, 0 \cdot 1 \mathrm{M}$, pH $8 \cdot 6$, on cellulose acetate (Oxoid). Strip fixed, cut lengthwise. Half of strip stained with Ponceau $S$ to locate proteins; other half cut in $2 \mathrm{~mm}$. sections which were dissolved in scintillation fluid for radioactivity counts

rendered dialysable after treatment with bacterial hyaluronidase. To achieve a high specific yield of hyaluronic acid, they used glucosamine as substrate, which in turn required low glucose levels and addition of pyruvate to the culture medium.

Incorporation of glucose into macromolecules other than hyaluronic acid has also been found in the present studies. The proportion varies greatly, but in the fractions containing the largest macromolecules, from either Sephadex G200 or agarose, glucose appears almost entirely as hyaluronic acid for culture periods as long as 5 days. Radioactive hyaluronic acid can thus be readily purified from culture medium containing isotopic glucose as a precursor rather than glucosamine, which simplifies the culture technique and also appears to permit labelling of both glucosamine and glucuronic moieties of the molecule.

The other cell secretions derived from glucose have not been fully identified. Glucose might have been transformed to any of the saccharides in glycoproteins, or to amino acids and then to proteins. Of the three amino acids studied, proline entered only the fraction of largest molecules, which is consistent with the formation of soluble collagen. Synovial cell cultures are known to synthesize collagen (Castor and Muirden, 1964). The appearance of leucine in the same fraction might also represent synthesis of collagen, but tryptophane, which is virtually absent in collagen from any source (Lowther, 1963), appeared in the same zone. This suggests the secretion of either a distinct large protein or peptide incorporated in the proteoglycan, or the recently described compound of collagen with noncollagen peptides (Church, Pfeiffer, and Tanzer, 1971). Since the gel chromatographic pattern of this fraction was not altered by bacterial hyaluronidase, it cannot rep- resent small peptides incorporated in the structure of hyaluronic acid. Kitlowski, Mooney, Rodnan, and Mankin (1965) found that segments and slices of rabbit synovium and cartilage incorporated glycine, histidine, proline, and tryptophane for up to 6 hours. Uptake of proline was slower than the others in contrast with that of tryptophane which was the most rapid.

The other major class of labelled macromolecules separated by gel chromatography elutes in the zone of serum albumin which gives an indication of their molecular size. Glucose, leucine, and tryptophane appear in this zone, but not proline or sulphate. Leucine and tryptophane cannot be transformed to saccharide by mammalian cells and their incorporation thus indicates the formation of protein. As noted, glucose might reappear as saccharide or peptide, but since it did not appear to enter proteins in Fr. 1 after 5 days' cumulative exposure, it seems likely that it remained as saccharide in Fr. 2. The evidence thus points to secretion of glycoproteins. The rapid electrophoretic migration of the main component in this group is consistent with a highly charged glycoprotein, but this group of substances needs further characterization by hydrolysis and other methods.

The pattern obtained with sulphate suggests the synthesis of chondroitin sulphate, but the other evidence given, and previous moving-boundary electrophoresis (Fraser and McCall, 1965), indicates that this is a very small proportion of the total glycosaminoglycans in contrast with those formed by cartilage cells (Harris, Martin and Muirden, 1972).

\section{Summary}

Cell cultures derived from human synovial cells were exposed to radioactive substrates of glucose, amino acids, and sulphate. Glycosaminoglycan secreted by these cells appeared to be predominantly hyaluronic acid. Highly polymerized and purified radioactive hyaluronic acid could be prepared from glucose substrate with sequential chromatography in Sephadex G200 and agarose, or in a single step with agarose alone and without prior dialysis.

Fractionation with Sephadex G200 also separates two groups of soluble cell products distinct from glycosaminoglycans. The group with the larger molecular size includes at least one class of protein which may be distinct from collagen; the smaller group is an electrophoretically fast class of protein which appears to be glycoprotein.

We are grateful to Miss Sue Eager, B.Sc., for technical assistance. The work was supported by grants from the Arthritis and Rheumatism Council for Research in Great Britain and the Commonwealth, the Australian Rheumatism Council, and the National Health and Medical Research Council of Australia. 


\section{References}

BARker, S. A., AND Young, N. M. (1966) Carbohydrate Res., 2, 363 (Isolation of hyaluronic acid by gel filtration on agarose)

Barland, P., Smith, C., ANd Hamerman, D. (1968) J. Cell Biol., 37, 13 (Localization of hyaluronic acid in synovial cells by radioautography)

Bray, G. A. (1960) Analyt. Biochem., 1, 279 (A simple efficient liquid scintillator for counting aqueous solutions in a liquid scintillation counter)

CASTOR, C. W., AND Fries, F. F. (1961) J. Lab. clin. Med., 57, 394 (Composition and function of human synovial connective tissue cells measured in vitro)

-, AND MUIRdEN, K. D. (1964) Lab. Invest., 13, 560 (Collagen formation in monolayer cultures of human fibroblasts)

Church, R. L., Pfeiffer, S. E., AND Tanzer, M. L. (1971) Proc. nat. Acad. Sci. (Wash.), 68, 2638 (Collagen biosynthesis: Synthesis and secretion of a high molecular weight collagen precursor (Procollagen))

Clarris, B. J., AND Fraser, J. R. E. (1968a) Aust. J. exp. Biol. Med. Sci., 46, 107 (Some factors influencing the reactions of human synovial cells in vitro with fresh homologous and autologous serum)

_- (1968b) Exp. Cell Res., 49, 181 (On the pericellular zone of some mammalian cells in vitro)

Daniel, M. R., Dingi.E, J. T., AND LuCY, J. A. (1961) Ibid., 24, 88 (Cobalt-tolerance and mucopolysaccharide production in rat dermal fibroblasts in culture)

Dulbecco, R., AND VoGt, M. (1954) J. exp. Med., 99, 167 (Plaque formation and isolation of pure lines with poliomyelitis viruses)

Evanson, J. M., JefFrey, J. J., AND Krane, S. M. (1967) Science, 158, 499 (Human collagenase: Identification and characterization of an enzyme from rheumatoid synovium in culture)

Flodin, P., AND KIllander, J. (1962) Biochim. biophys. Acta, 63, 403 (Fractionation of human serum by gel filtration)

Fraser, J. R. E. (1963) 'Tissue Culture', in 'Report of the Arthritis and Rheumatism Council Symposium on Cytological Aspects of Joint Tissues, London, November, 1963, p. 37.

- AND MCCALL, J. F. (1965) Ann. rheum. Dis., 24, 351 (Culture of synovial cells in vitro)

Grossfeld, H., Meyer, K., Godman, G., AND Linker, A. (1957) J. biophys. biochem. Cytol., 3, 391 (Mucopolysaccharides produced in tissue culture)

HARRIS, G. S., AND Fraser, J. R. E. (1969) J. Lab. clin. Med., 74, 527 (Extraction and measurement of glycoaminoglycans in serum and cell culture medium: A system with the use of an aliphatic quaternary ammonium salt)

-, MARTIN, T. J., AND MUIRDEN, K. D. (in press) (Synthesis of glycosaminoglycans and other macromolecules by embryo calf epiphyseal cells in culture). Calcif. Tiss. Res.

JACKson, S. F., AND Smith, R. H. (1957) J. biophys. biochem. Cytol., 3, 897 (Studies on the biosynthesis of collagen. 1. The growth of fowl osteoblasts and the formation of collagen in tissue culture)

Janis, R., SANDSON, J., Smith, C., AND Hamerman, D. (1967) Science, 158, 1464 (Synovial cell synthesis of a substance immunologically like cartilage proteinpolysaccharide)

Kitlowski, N. P., Mooney, V., Rodnan, G. P., And Mankin, H. J. (1965) Arthr. and Rheum., 8, 452 (Protein synthesis in articular cartilage and synovium of the rabbit)

Lowther, D. A. (1963) Int. Rev. conn. Tissue Res., 1, 63 (Chemical aspects of collagen fibrillogenesis)

OGston, A. G., AND STANIER, J. E. (1952) Biochem. J., 52, 149 (Further observations on the preparation and composition of the hyaluronic acid complex of ox synovial fluid)

PORTER, K. R., AND PAPPAS, G. D. (1959) J. biophys. biochem. Cytol., 5, 153 (Collagen formation by fibroblasts of the chick embryo dermis)

Scotr, J. E. (1962) Biochem. J., 82, 43P (Separation and measurement of the products of reaction of phenyl isothiocyanate with galactosamine and glucosamine)

Tishler, P. V., AND EPSTEIN, C. J. (1968) Analyt. Biochem., 22, 89 (Convenient method of preparing polyacrylamide gels for liquid scintillation spectrometry) 